\title{
A review on herbal drug loaded into pharmaceutical carrier techniques and its evaluation process
}

\author{
Sandhiya $V^{*}$ and Ubaidulla $U$
}

\begin{abstract}
Background: The herbal drug is molded in nanocarriers to boost growing interest in a pharmaceutical era for various fields in sort to amplify therapeutic worth. Nowadays, a promising interest has been developed in nanotechnology using herbal medicines as core material to provoke its activity on the target site.

Main body: By administering herbal medicine in the nano-size form, there are chances for improving the bioavailability, binding receptor selectivity due to higher active surface energy thereby enhancing the effectiveness and safety of the active entity. In the last few decades, formulations with nano-sized herbal active ingredients have emerged as nano-phytomedicines owing to its wide range of interest and effectiveness because of its unique nature. Nanonized drug delivery structure of herbal drug has an approaching outlook for getting bigger the doings and overcome problems associated with plant medicine. The current review will focus on nanoparticles, herbal drug-loading techniques, herbal nanoformulations, and applications in various fields.

Conclusion: We conclude that by formulating herbal drug in nanocarriers would be a promising guide for the progress of core remedy and will act as a promising proposal for many pathological conditions.
\end{abstract}

Keywords: Nanoformulations, Herbal drug-loading technique, Application

\section{Background}

Nano-size particle or nanoparticle is a spacious class of materials that enclose particulate substance which has not as much of $100 \mathrm{~nm}$ in size [1]. It is a well-known field of research of this century and it has a wide range of revolutionary developments in the field of nanotechnology such as treatment, monitoring, diagnosis, and control of biological systems.

Nanoparticles or nanomaterials have gained prominent advancements in nanotechnology due to their tunable physiochemical and biological performance over their counterparts [2]. The major drawbacks of conventional are nonspecific, lack of solubility, and inability to enter inside the cells which offer a great opportunity for nanoparticles to play significant roles.

* Correspondence: sandhiyavaithi@gmail.com

Department of pharmaceutics, C.L.Baid Metha college of pharmacy, Thoraipakkam, Chennai 600097, India

Springer Open
Herbal medicines have been extensively used in the region of the world since antique times. In india herbal medicines or traditional system of medicines such as Siddha and Ayurveda use herbal preparations [3]. Nowadays, herbal drugs dwell in a leading position in the pharmaceutical industry as their effects are known and side effects are very negligible. Moreover, the herbal drug has a symmetrical way of interest to fabricate nanoparticles compared to synthetic drugs [4]. Even though the herbal drug has enormous pharmacological actions toward many diseases, it has been shown an only limited effect on the human biological system due to their less kinetic performance such as low absorption, inability to cross lipid membrane, high molecular size and weight, or poorly absorbed, resulting in a reduction of bioavailability and efficacy over the biological system [5]. Moreover, some of the extracts are not used clinically because of the abovementioned hinders. To overcome such

(c) The Author(s). 2020 Open Access This article is licensed under a Creative Commons Attribution 4.0 International License, which permits use, sharing, adaptation, distribution and reproduction in any medium or format, as long as you give appropriate credit to the original author(s) and the source, provide a link to the Creative Commons licence, and indicate if changes were made. The images or other third party material in this article are included in the article's Creative Commons licence, unless indicated otherwise in a credit line to the material. If material is not included in the article's Creative Commons licence and your intended use is not permitted by statutory regulation or exceeds the permitted use, you will need to obtain permission directly from the copyright holder. To view a copy of this licence, visit http://creativecommons.org/licenses/by/4.0/. 


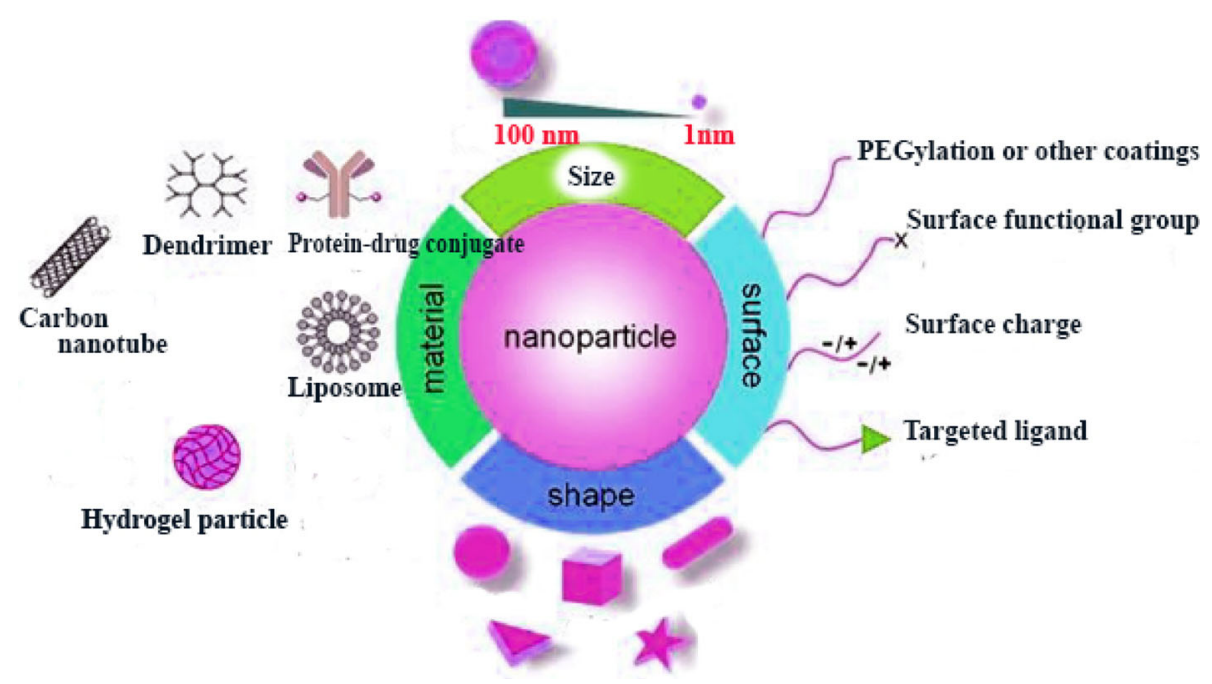

Fig. 1 Schematic representation of nanoparticles

related issues, carriers have been used as an alternative approach to amend and improve the kinetic and dynamic parts of a drug molecule on a biological system.

In recent decades, an herbal drug with nanocarriers has received a lot of attention with enthusiasm because of its future potential and its unique properties making these materials indispensable in many areas of human activity. So nano herbal systems have a promising prospect for raising the activity and overcoming the dilemma allied with plant remedy.

The major necessitate of the herbal drug has nanocarriers are before to reaching into the bloodstream the activity of drugs will be ruined in the highly acidic $\mathrm{pH}$ of the stomach or might to metabolized by the liver $[6,7]$. Because of these short of optimal amount on the affected region, there will be no means to be evidence for the therapeutic effect of the drug, so to progress the bioavailability and therapeutic activity of the herbal drug molecule on the affected region and to prevent the drug from the acidic environment, the drug has been formulated using carriers.

Nanoparticles are classified based on many forms, such as based on materials, based on size, based on surface, and based on shapes [8]. Example based on coating materials and ligand anchor over the nanoparticles and based on the use for the study purpose the classification of nanoparticles will be represented (Fig. 1).

Nanocarriers or nanostructure systems can be broadly divided into organic and inorganic. The physiochemical properties of these carriers can be tuned by altering their composition or dimension [7]. Nanocarriers' application to herbal remedies will provide more surface area and enhanced solubility, bioavailability, and facilitate exact drug targeting which is an endeavor to release a drug molecule over a particulate area of the system for a prolonged period to elicit a response on diseased tissue.

Nanocarriers are important to deliver a potent drug on the needed region in our body to elicit a potent pharmacological reaction. Nanocarriers are classified based on carrier materials' used, such as organic and inorganic carriers [9]; those carriers are chosen to carry the active drug based on the kinetic property of the moiety (Fig. 2).

\section{Common nanoformulation systems loaded with herbal active ingredients}

Nanotechnology is one of the input novel drug delivery methods under examination, with nanoformulation attention to have a wide variety of benefits in contrast with conventional preparations of plant constituents, which include improved permeability, solubility, bioavailability, therapeutic action, stability [10, 11], enhanced allocation within tissues, and persistent delivery.

Over the past decades, various nanotechnology-based systems such as the following:

1. Polymeric nanoparticles

2. Solid lipid nanoparticle

3. Magnetic nanoparticles

4. Metal and inorganic nanoparticles

5. Quantum dots

6. Polymeric micelles

7. Phospholipids micelles 


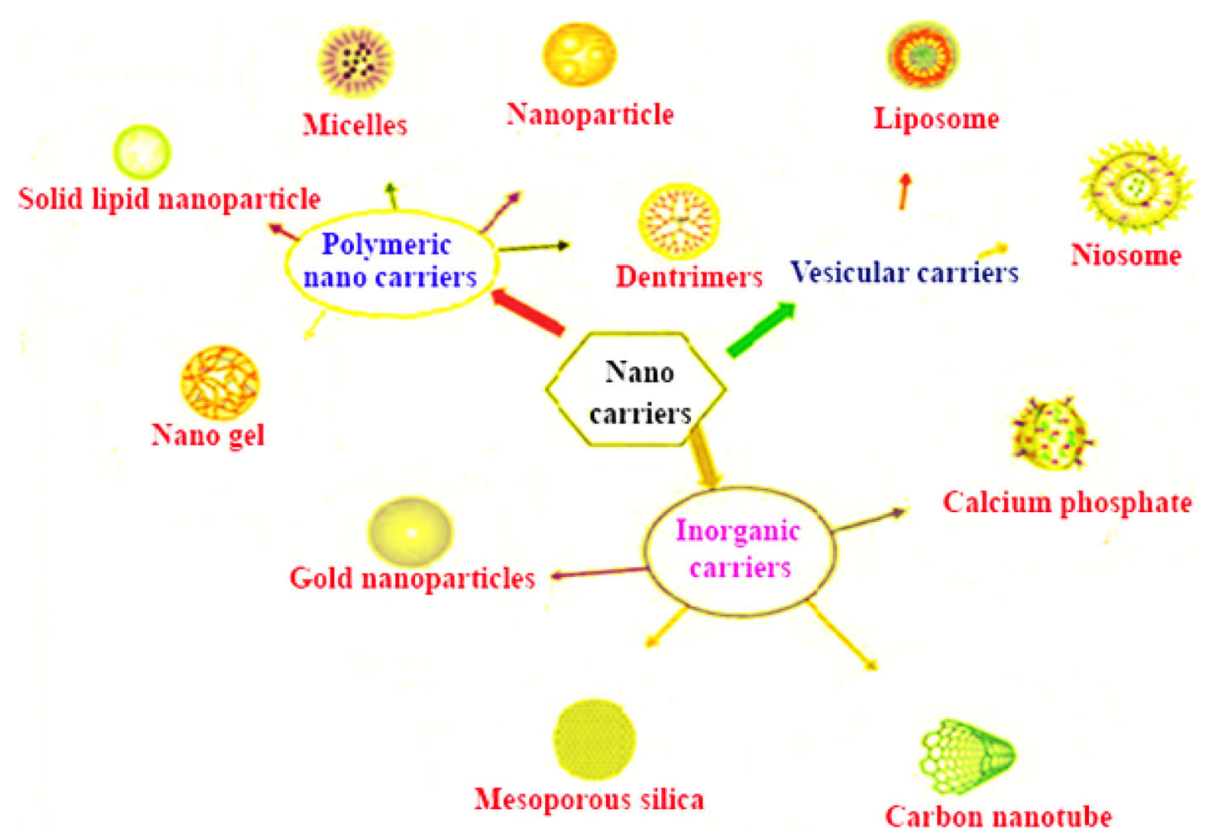

Fig. 2 Nanocarriers

8. Colloidal nano-liposomes

9. Dendrimers are being available in the pursuit to improve aqueous solubility and drug delivery to the pathological site [12].

10. Metal-organic framework (MOF) nanoparticles (zeolitic imidazolate framework) are essentials to form strong interaction between drugs to increase the drug-loading efficacy. The nanoparticle based on metal-organic framework can comprehensively enhance the immunotherapy of various therapeutic agents $[13,14]$.

11. Micelle carrier, the stable micelles, may exhibit improved photothermal efficiency toward cancer cells for both in vitro and in vivo studies [15].

Nanotechnology for herbal drug (Anticancer Res. $2016,35,15821614$ ) have reported by loading herbal active entities in the above carriers is therapeutically effectual against several human conditions [16], owing to its anti-inflammatory, antioxidant, antibacterial, anticancer, wound healing properties, etc. [17] compared to conventional form.

Nanoparticles with different morphologies. 0-D, 1$D$, and 2-D are the different dimensions of nanoparticles, mesoporous [18], liposomes, and micelle and are entirely made up of lipids, and there spherical structures are amphiphilic compound; the dendrimer is branched-type compound. Polymeric nanoparticles and hydrogels are completely made by natural and synthetic polymers; they are usually more stable in nature (Fig. 3).

\section{Main text}

\section{Herbal drug loading}

Herbal drugs are becoming more popular in the modern world for their application to cure a variety of diseases with less toxic effects and better therapeutic effects [19]. On the other hand, a few limitations of herbal extracts are unstable in highly acidic $\mathrm{pH}$, high first-pass metabolism, etc. [20], may lead to drug level below the therapeutic concentration in the blood resulting in less or no therapeutic effect [21]. To abolish such effects, the herbal drugs are loaded into the novel carriers to minimize drug degradation and severe side effects by the accrual of drugs to the non-targeted area [22] (Fig. 4).

Phytoconstituent-loaded nanoparticles were formulated by the following steps; initially, the phytoconstituents have to extract from the plant and then have been formulating into nanomaterial-loaded phytoconstituents, then this has been promoting pharmacological effect in the desired form [23].

\section{Techniques for loading nanoparticles}

1. Hot homogenization technique

2. Cold homogenization technique

3. High-pressure homogenization method

4. Complex coacervation method

5. Coprecipitation method, self-assembly methods 


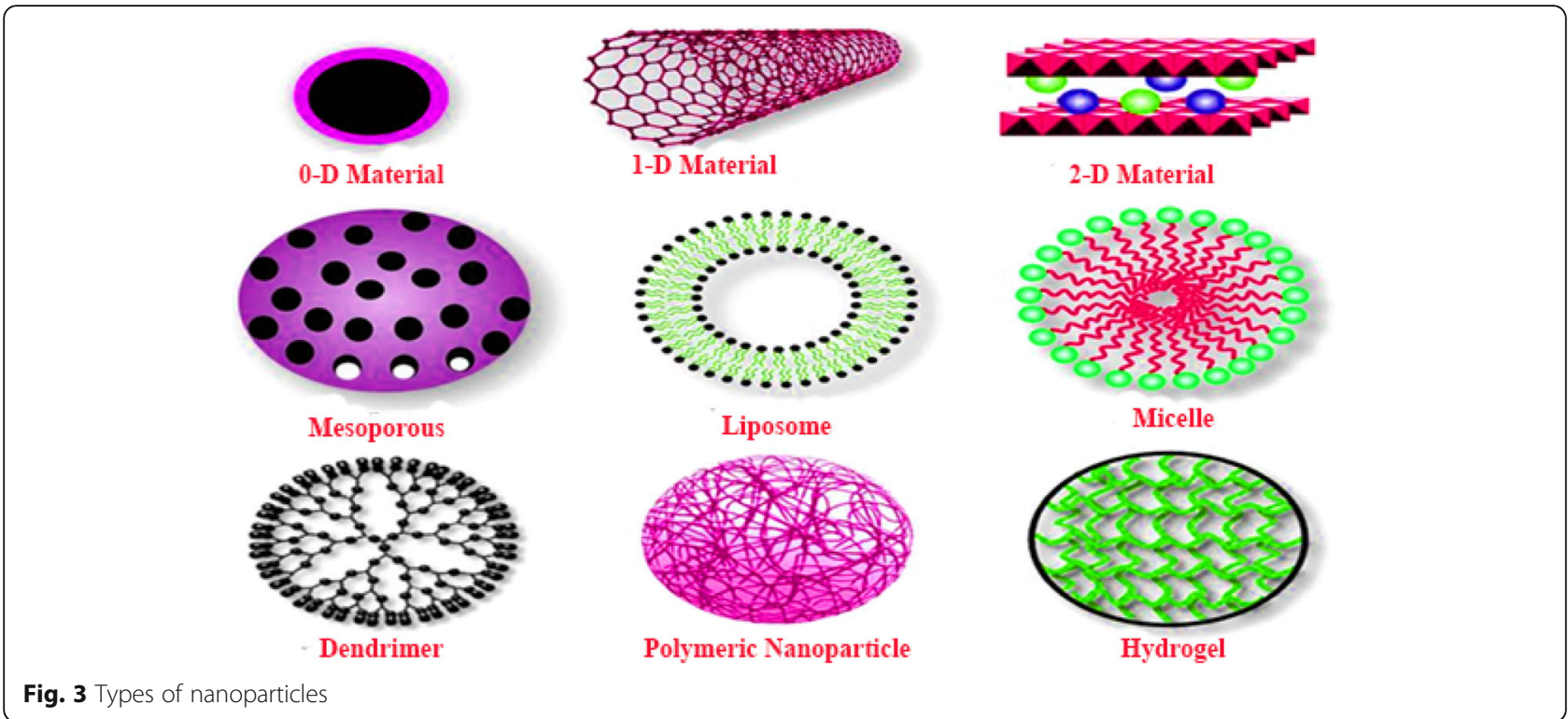

6. The salting out method, supercritical fluid method

7. Nanoprecipitation method or solvent displacement method

8. The solvent emulsification diffusion method

\section{Hot homogenization}

This process will take place in the presence of a higher temperature than the melting point of the lipid $[24,25]$. The pre-emulsion will form when the drug is loaded with melted lipids in the presence of a hot aqueous solution of surfactants. Finally, the nanoparticles will be formed.

\section{Cold homogenization technique}

In this approach, the drug is melted in the lipid melt, and quickly cooled using cryogenic systems like liquid nitrogen or ice nitrogen. Then make it into dispersing powder form using powder mill. Then homogenize at room temperature or below to get a nanoparticle (Fig. 5).

Example: hot and cold homogenization techniques were mostly used to prepare lipid-based nanoparticles formulation.

\section{Solvent emulsification diffusion method}

The method involves the preparation of an o/w emulsion, oil phase contains polymer in presence of organic solvent and aqueous phase contain stabilizer [26], which are emulsified using a high shear mixer, followed by adding up of water to provoke the diffusion of organic solvent, thus consequential in development of nanoparticles (Fig. 6). Example: breviscapine liposomes for CVS disease, cyclosporine-loaded sodium alginate glycolate technique, and doxorubicin-loaded nanosphere or nanocapsules [27]

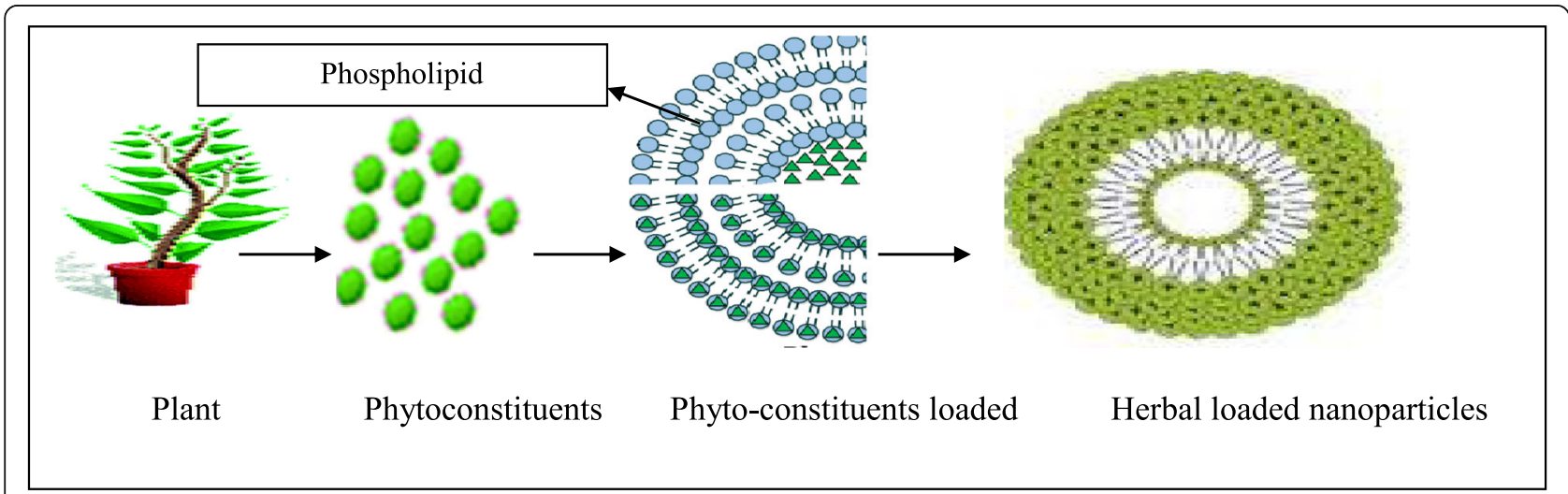

Fig. 4 Herbal drug-loaded nanoparticles 

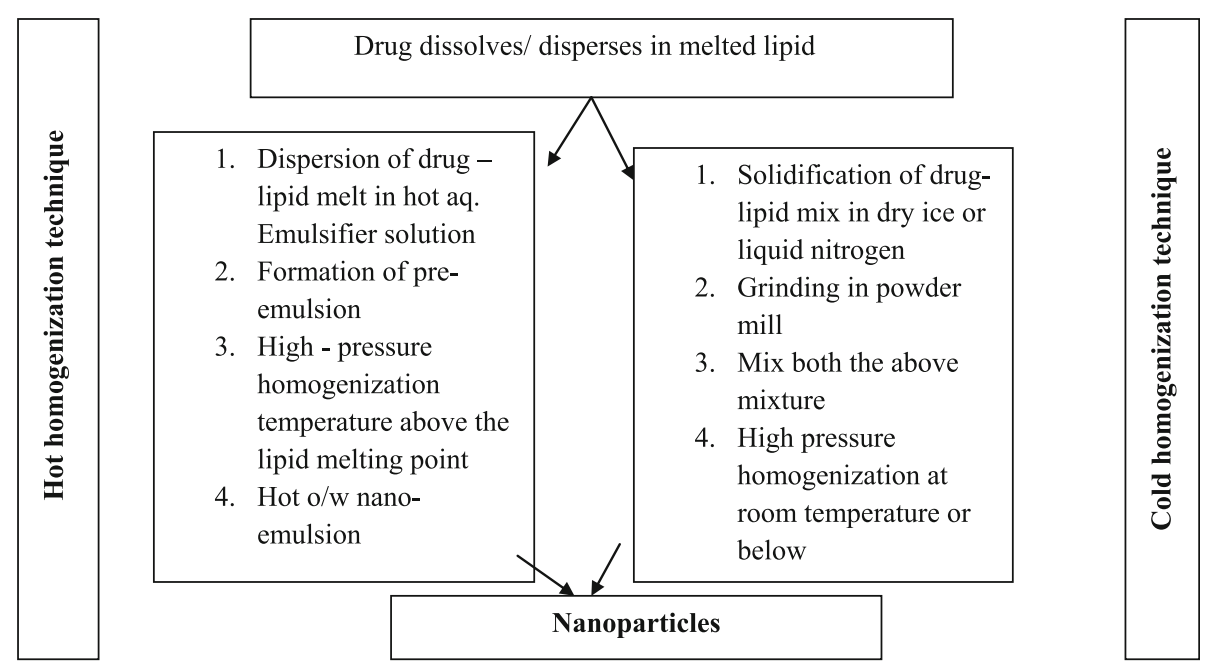

Fig. 5 Hot homogenization and cold homogenization loading technique

\section{Complex coacervation method}

This is a spontaneous phase-separation process of two liquid phases in colloidal systems, which results in the interaction of two oppositely charged polyelectrolytes upon mixing in an aqueous solution.

Example: coacervation or ionic gelation method has been focused for the preparation of nanoparticles using biodegradable hydrophilic polymers such as chitosan, sodium alginate, and gelatin [28]. This method has been used for the preparation of chitosan nanoparticles.

\section{Coprecipitation method}

This method is an amendment of the composite coacervation method for the preparation of nano-size particles [29]. This method has been reported to afford good dispersal stability to feebly water-soluble drugs.

\section{Salting out method}

This method is based on the event that the solubility of a non-electrolyte in water is decreased in the lead adding up of an electrolyte [30].

Example: nanospheres are formulate by salting out method, initially in a solvent, polymer and drug are dissolved which is consequently containing the salting out agent [31] (electrolytes), most commonly, this technique uses for heat sensitive substances.

\section{Supercritical fluid extraction of emulsion}

Supercritical fluid extraction of emulsion (Int.J.nanomed, 2017, 12, 2689) has been prepared through solid lipid nanoparticles using supercritical $\mathrm{Co}_{2}$. This technique uses supercritical fluid for removing the solvent from o/ $\mathrm{w}$ emulsion [32, 33]. The supercritical anti-solvent precipitation can serve as a substitute for supercritical fluid extraction of emulsions (Fig. 7).

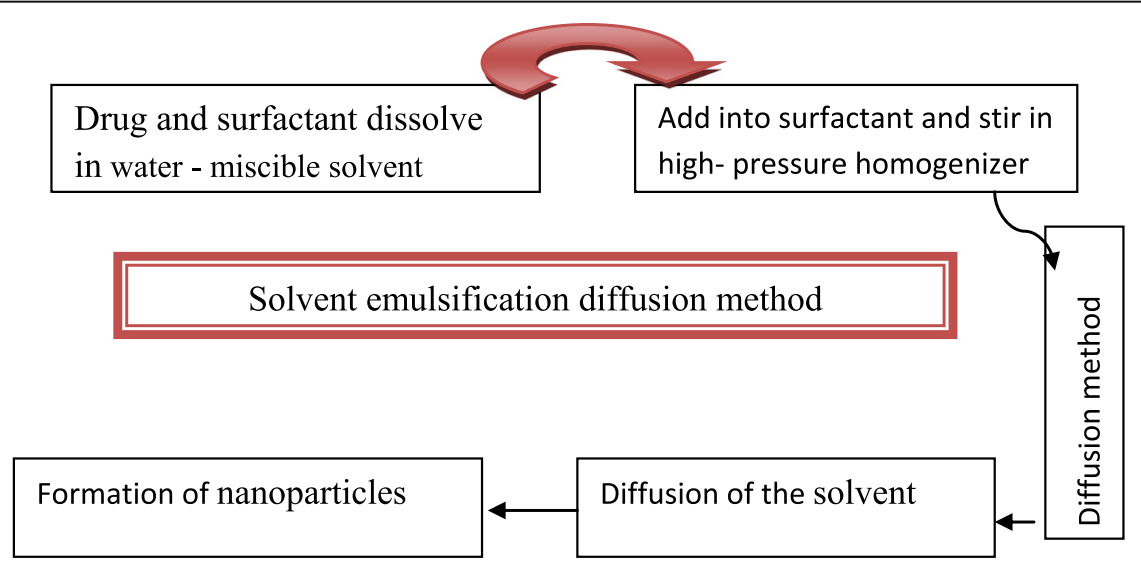

Fig. 6 Preparation of nanoparticle by solvent emulsification diffusion method 
Nanoprecipitation method or solvent displacement method This method is based on interfacial accrual of a polymer after dislocation of a semi-polar solvent miscible with water from a lipophilic solution, thereby ensuing in a dwindle in the interfacial tension between the two phases [34, 35], which increase the shell area with a consequent configuration of small droplets of organic solvent even devoid of any mechanical stirring.

Example: for most of the poorly soluble drugs, nanoprecipitation method is well suited. By adjusting preparation parameters, nanosphere size and drug release can be controlled effectively.

\section{Mechanism of cellular uptake of nanoparticles and their effect on drug delivery}

In the field of diagnosis and treatment in contemporary medicine, nanoparticles (NPs) are an important novelty. They are drug delivery systems on the nanometer scale, whose uptake mechanisms and routes of internalization differ, depending on their properties. For successful treatment, it is crucially important to understand the interplay between uptake mechanisms and NP properties [36]. In this article, mechanisms of NP uptake and the subsequent intracellular events are presented. NPS can enter cells via phagocytotic or non-phagocytotic pathways (clathrin-mediated endocytosis, caveolae-mediated endocytosis, macropinocytosis, and other endocytotic pathways). The route of internalization determines the site of drug release, which can be in the acidic and enzyme-rich environment of lysosomes, or NPS avoid this compartment and release drugs in the cytosol or another organelle. This process can be controlled by a careful selection of NP ingredients and precise design of their physicochemical properties (size, shape, surface properties). Phagocytosis is generally undesirable, since its main purpose is the elimination of foreign materials from the body, and therefore the drug taken up in this way is usually lost. To avoid this internalization mechanism, the particles should be small showing a hydrophilic surface [37]. However, the most successful approach is to attach ligands to the NP surface, which governs the uptake through non-phagocytotic mechanisms. Knowledge about cellular uptake mechanisms is crucial for predicting drug delivery to the target site in the cell since it can lead to better stability of NPs and preserved biological activity of labile drugs.

The nanoparticles were mostly internalized into the cells by clathrin and caveolae independent and dependent endocytosis pathway [38]. The dependent pathway is involved in cell signaling and regulation of membrane proteins, lipids, and fatty acid.

The interdependent pathway is involved in the utilization of growth hormone, extracellular fluid, GPIlinked protein, and interleukins-2.

Mostly, those pathways were utilized for internalization of micron-sized nanoparticles which are not feasible to be taken up into the cells $[39,40]$. The nanoparticles can enter by macropinocytosis or phagocytosis process.

In macropinocytosis, all dissolved particles in the extracellular fluid are taken into the endocytic vesicle, despite the presence of their precise receptors, making the process a form of nonspecific bulk fluid uptake.

Nanoparticle size between 25 and $50 \mathrm{~nm}$ is required for the finest endocytosis and intracellular localization.

Steps detailing the cytosolic delivery of therapeutic agents via nanoparticle carriers [41]

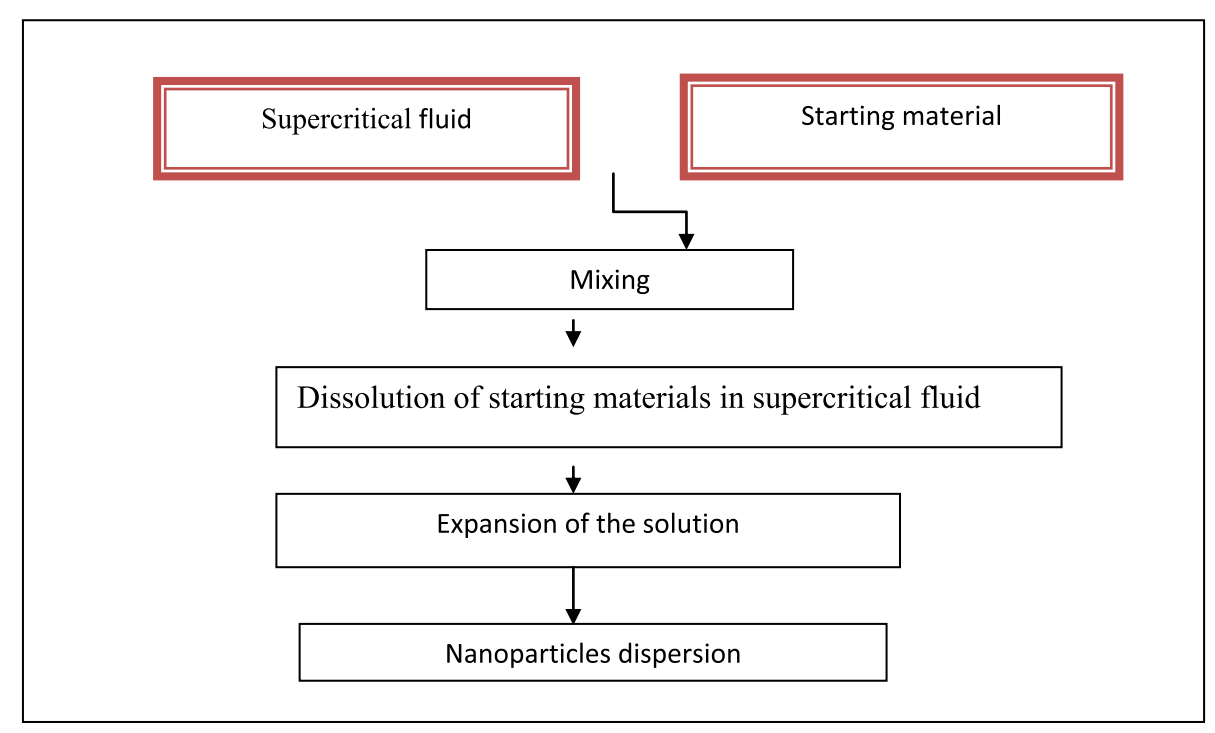

Fig. 7 Supercritical fluid extraction of emulsion 
(1) Cellular organization of nanoparticles

(2) Internalization of nanoparticles using endocytosis

(3) Endosomal break away from nanoparticles or

(4) Lysosomal deprivation of nanoparticle

(5) Therapeutic agent generously diffuses into the cytoplasm.

(6) Cytoplasmic transfer of therapeutic moiety to intentional organelle

(7) Exocytosis of nanoparticles

\section{Phagocytosis of nanoparticles}

Usually, initiated by opsonization, opsonins such as immunoglobulins, complement proteins, or other blood proteins (e.g., laminin and fibronectin) are adsorbed onto the nanoparticle surface. Opsonized nanoparticles are then accepted by, and attach to phagocytes via specific ligand-receptor interactions. This initializes a signaling surge that can activate actin assembly, the formation of cell surface extensions, and successive engulfing and internalization of particles, forming what is known as a "phagosome."

Therefore, mentioned events take between $30 \mathrm{~min}$ to several hours, depending on cell type and the nature of the particle surface. Phagocyte receptors concerned in this process contain Fc receptors and complement receptors (Fig. 8).

Nanoparticles initially form a complex by binding with immunoglobulins, and that process is called opsonization [42]. Then the complex formation binds with phagocyte which is named as complement activation process. The engulfment of the activated complex by phagocyte is called phagocytosis.

Nanoparticles are classified into organic, inorganic, and carbon-based nanoparticles. The examples for organic nanoparticles are dendrimers, liposomes, and micelles. The examples for carbon-based nanoparticles are graphene and fullerene. The example for inorganic nanoparticles is further divided into metal-based and metal oxide-based forms (Fig. 9).

\section{Herbal formulations}

Herbal remedies were chosen as feasible drug molecule for delivery through nanocarriers as a promising delivery system [43]; the main reasons for the popularity of herbal medicines are as follows (Table 1):

1. Deliver in high concentration may increase the unique size and high loading capacities

2. May persist at the site for a longer time

3. 3. May have fewer side effects

4. May decrease the dose of the drug formulation

As per the World Health Organization (WHO), in developing countries, around $80 \%$ of the world populations at present utilize herbal medicine for primary health care. Presently, the scientific community is focused on the study associated with the bioactive compounds, its chemical composition, and pharmacological potential of a variety of plant species, to fabricate pioneering active ingredients that present moderately minor side effects than existing molecule [58].

The number of synthetic molecules that are essentially marketed is departing on diminishing day by day and thus investigate on the creation of the natural-based active compounds are again approaching to the attention in spite of its hurdles [59].

Several drugs that also possess natural therapeutic agents in their composition are already available commercially; their applications and names are as follows [46]: malaria treatment (Artemotil derived from

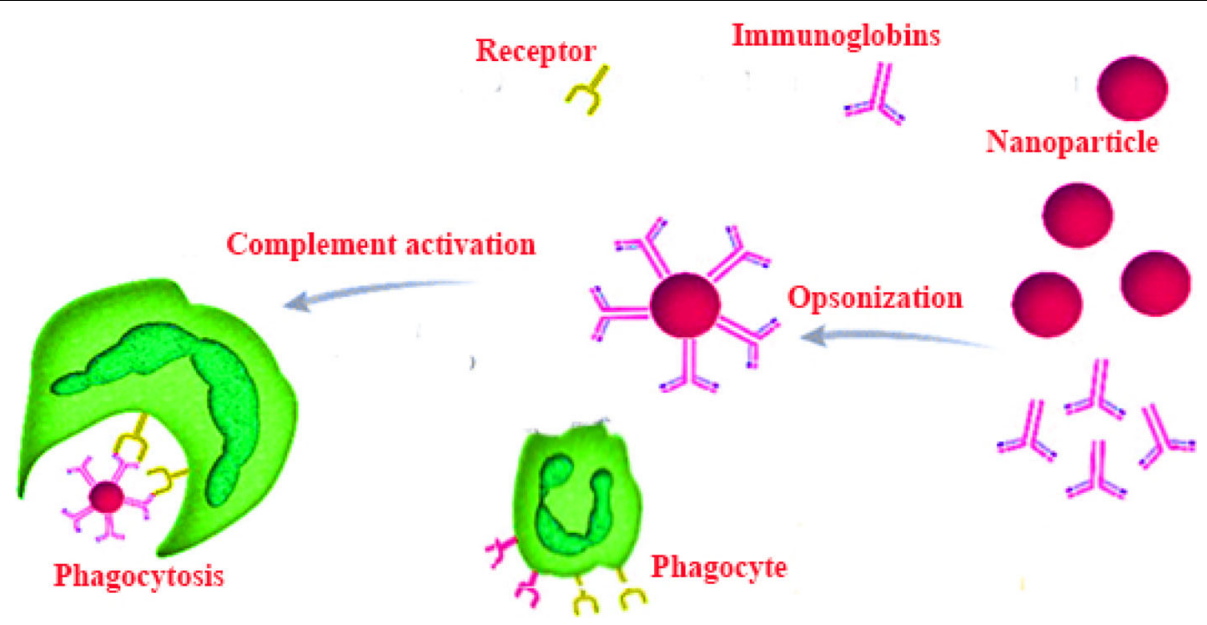

Fig. 8 Phagocytosis process of nanoparticles 


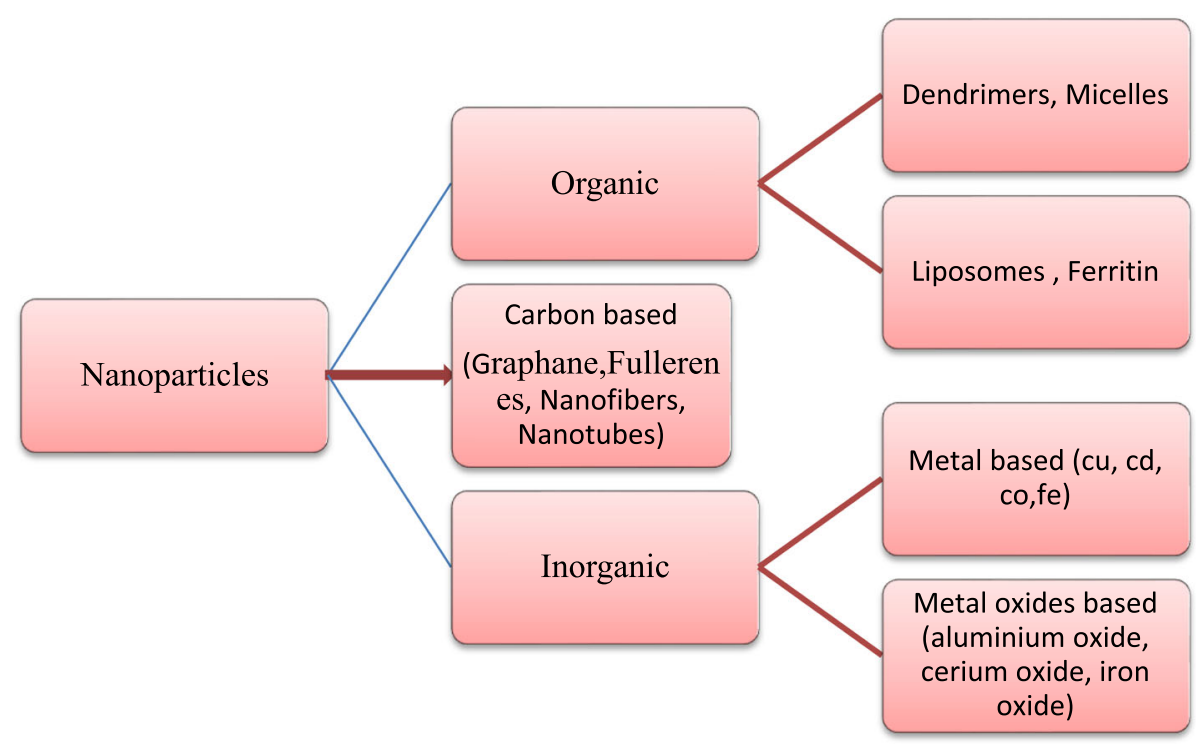

Fig. 9 Nanoparticles' classification

Artemisia annua, a traditional Chinese medicine plant) and cancer treatment (paclitaxel and its analogs derived from the Taxus brevifolia plant; vinblastine and vincristine extracted from Catharanthus roseus; liver disease (silymarin from Silybum marianum)).

In the last few decades, substantial notice has been focused on the progress of herbal drug in a novel drug delivery system [60, 61]. The novel carriers should preferably accomplish two prerequisites.

1. Should transport the drug directly base on the necessitate of the body throughout treatment
2. Should discharge the active moiety of the herbal drug at the spot of action

\section{Evaluation of nanoparticles}

X-ray powder diffraction (XRD)

A rapid systematic method used for phase detection of the crystalline material and can endow with information on unit cell measurement and atomic spacing [62]. The $\mathrm{X}$-ray is produced by cathode ray tube, potable to fabricate monochromatic radiation, collimated to on purpose, and projected toward the sample [63].

Table 1 Herbal formulations

\begin{tabular}{llll}
\hline S.no & Formulations & Active ingredients & Function \\
\hline 1 & Curcuminoid solid lipid nanoparticles & Curcuminoids & Anticancer and antioxidant [44] \\
2 & Artemisinin nanocapsules & Artemisinin & Anticancer [45] \\
3 & Berberine-loaded nanoparticles & Berberine & Anticancer [46] \\
4 & Silybin nanoemulsion & Silybin & Hepatoprotective [47] \\
5 & Rutin-alginate-chitosan microcapsules & Rutin & Cardiovascular disease [48] \\
6 & Camptothesin-loaded microsphere & Camptothesin & Anticancer [49, 50] \\
7 & Docetaxel submicron emulsion & Docetaxel & Anticanerl activity [51] \\
8 & Curcuma-phospholipid complex & Curcumin & Anticancer [52] \\
9 & Gugulipid proniosome gel & Gugulin & Anti-liver toxicity [53] \\
10 & Chitosan nanoparticles of Camellia sinensis & Catechins & Antiviral, anti-inflammatory [54] \\
11 & Naringenin nanoparticle & Naringenin & Hepatoprotective [55] \\
12 & Tetrandrine-loaded nano-aggregates & Tatrandrine & Rheumatoid arthritis, psoriasis [44] \\
13 & Curcumin-loaded PLGA nanosphere & Curcuminoids & Antiplatelet, antioxidant [56] \\
14 & Quercetin microemulsion & Quercetin & Anti-parasitic, anti-angiogenic [57] \\
\hline
\end{tabular}


Thermogravimetric analysis/differential thermal analyzer Thermogravimetric analysis (TGA) is a thermal analysis method which deals with the weight change in a substance as a utility of temperature and time, in a proscribed environment [64]. It is appropriate for use with all types of solid materials, including organic or inorganic materials.

Differential thermal analysis is a calorimetric technique, soundtrack the temperature, and heat surge related to thermal transitions in a substance [65]. This enables stage transitions to be resolute (e.g., melting point, glass transition temperature, crystallization). Thermogravimetric analysis (TGA) is a type of testing performed on samples that determines changes in weight about change in temperature.

\section{Particle size, polydispersity index}

The particle size and polydispersity index of materials can be analyzed by a dynamic light scattering method at a set angle and optimized temperature. This method is used to reveal the surface charge and physical stability of the formulation.

\section{Transmission electron microscopy (TEM)}

The structural surface and shape of carriers and the formulation can be easily investigated by transmission electron microscopy [66]. First, the samples should be diluted with distilled water then place a drop on a 200 mesh carbon film covered copper grid and further stained with a suitable staining solution. Dry the sample and analyze the shape.

\section{Dynamic light scattering}

It is the fastest method for determining the particle size. Commonly used for the size determination in colloidal particles in the nano and submicron range particles. The dynamic light scattering can also use for the determination of particle size distribution.

\section{Nuclear magnetic resonance}

Nuclear magnetic resonance is used for the estimation of both the qualitative nature and size of nanoparticle measurement. NMR can provide data about the physicochemical state of the constituent inside the nanoparticles.

\section{Determination of encapsulation efficiency and recovery}

The study aims to determine the encapsulation efficiency of the drug into the carrier. The sample was diluted with an organic solvent and sonicated in an ultrasonic bath for $30 \mathrm{~min}$ to extract drug. The resulted mixture was centrifuged for $10 \mathrm{~min}$ at suitable rpm and analyzed by HPLC or UV.

\section{Stability studies}

The common and conventional techniques by which stability of nanoparticle can be analyzed are as follows:

1. Transmission electron microscopy (TEM)

2. Dynamic light scattering

3. UV-visible spectroscopy (UV-Vis)

4. Zeta potential

\section{UV-visible spectroscopy}

A sample is placed between a light source and a photodetector [67]. The intensity of a beam of UVvisible light is calculated before and after the transitory through the sample. These measurements are compared at every wavelength to specify the sample's wavelength-dependent spectrum. The data is classically plotted as absorbance as a function of wavelength.

\section{Surface plasmon resonance}

Every nanoparticle has its unique resonance absorption wavelength. The resonance condition is established when the frequency of light photons matches the natural frequency of surface electrons, oscillating against the restoring force of positive nuclei [68]. At the nanometer scale, particles put on view property are not inherent in individual atoms or to those in the bulk substance. The optical properties of nanoparticles are distinctly reliant on particle size and interpretable medium. When the nanoparticles move toward each other, they agglomerate owing to $\mathrm{pH}$ change, finally, UV can be used to learn the agglomeration of the particle.

\section{Zeta potential}

Zeta potential is an assessment of the efficient electric charge on the nanoparticle's surface, quantifying the charges. When a nanoparticle has a web surface charge, the charge is a screen by the concentration of ions of contradictory charges close to the nanoparticle surface [69]. These layers of oppositely charged ions move with the nanoparticle and collectively with the layer.

The magnitude of the zeta potential provides in sequence about particle stability. The higher the magnitude of potential exhibit amplified electrostatic revulsion and therefore amplified stability.

\section{Transmission electron microscopy}

TEM image provides the details about the size distribution and particle distribution of nanoparticles over the proposed shelf-life period. 


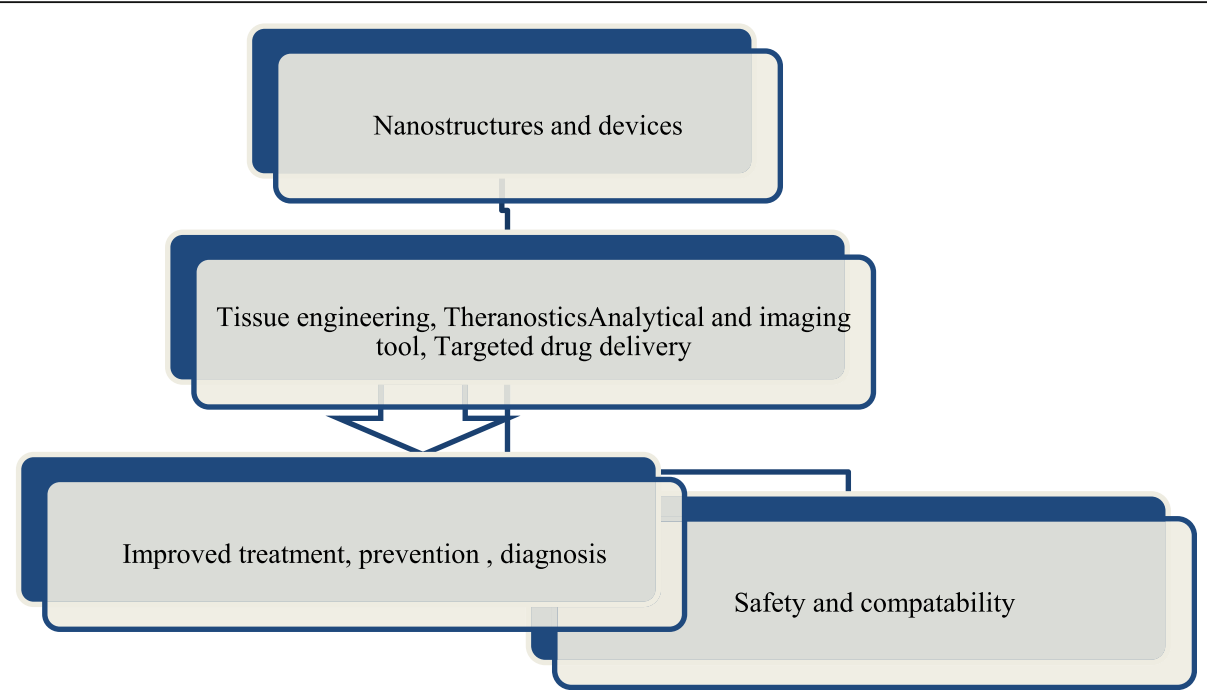

Fig. 10 Application of nanoparticles in various fields

\section{Atomic force microscopy}

By using this method can create a topological map of a sample and which is mainly based on the forces between the tip and the surface of the sample [70]. It is one of the most promising tools to obtain an ultrahighresolution of the particles.

\section{In vitro release}

In vitro release of herbal drug from the carrier was investigated using the dialysis bag method. Regenerate cellulose membranes were used to hold the carriers and permit the dispersal of the herbal drug into the discharge medium [71]. The drug-loaded carrier was deposited into the dialysis membrane and placed in release medium under optimized temperature and rpm [68]. A definite period interval samples were withdrawn and replaced with the same medium. Finally, the release was quantified by spectroscopy methods [72].

\section{Acoustic methods}

The technique determines the particle size by measuring the attenuation of sound waves and applying the physical equation [73]. The oscillating electric field twisted by the charged particle, progress under the direction of acoustic energy, which can be identified to afford information on the surface charge [74].

\section{SEM}

SEM micrographs have a large profundity of field acquiescent; they can give a characteristic three- dimensional appearance [75], useful for understanding the surface structure of a sample [76]. Under vacuum, electrons generated by a source are accelerated in a field gradient [77].

\section{Applications}

Application of nanomedicine in different field of biomedical research has been reported by Patravale et al. (Pharm Nanotec, 3(6), 293302) that the nanostructures and devices have various goals in a different field but the major core is to achieve the improved diagnosis, treatment, safety [78], and compatability (Fig. 10, Table 2).

Application of nanoparticles in various fields such as tissue engineering, theranostics, targeted drug delivery, analytical, and imaging tool [88] (Table 3).

The herbal drug has a growing interest in the safety of drug and surgery when conventional medicines are failed to promote effective treatment for most of the common health conditions.

\section{Future opportunities and challenges}

Nanoparticles and nanoformulation have previously been useful as drug delivery systems with immense accomplishment, and nanoparticulate drug delivery systems have still a better perspective for countless applications. In recent years, nano herbal preparation emerging a high interest in various fields due to its amorous pharmacological activity. Nanotechnology enables drug delivery is notch forthcoming future in pharmaceutics. 
Table 2 Application of different types of nanoparticles

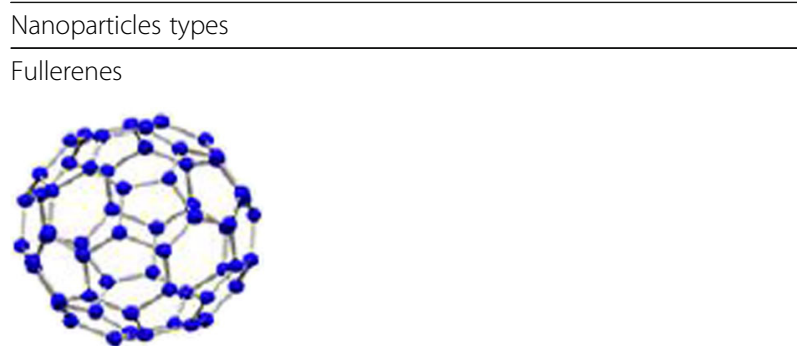

Eg: berberine-loaded fullerene $\left(C_{60}\right)$ for cancer (a molecule composed entirely of carbon [79])

1. Fullerene $\left(\mathrm{C}_{60}\right)$

2. Metallofullerol [31]

3. Cationic, anionic, and amino acid-type fullerene

Solid lipid nanoparticles( SLN)

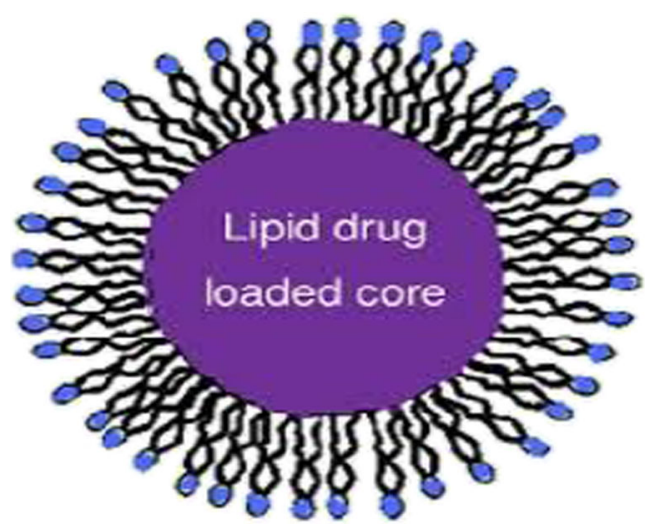

Eg: curcumin-loaded solid lipid nanoparticles (mainly comprise lipids that are in solid phase)

1. Glycerol palmitostearate and cetyl palmitate [80]

2. Hyaluronic acid-coupled chitosan SLN

3. Steric acid, soya

Nanostructured lipid carriers

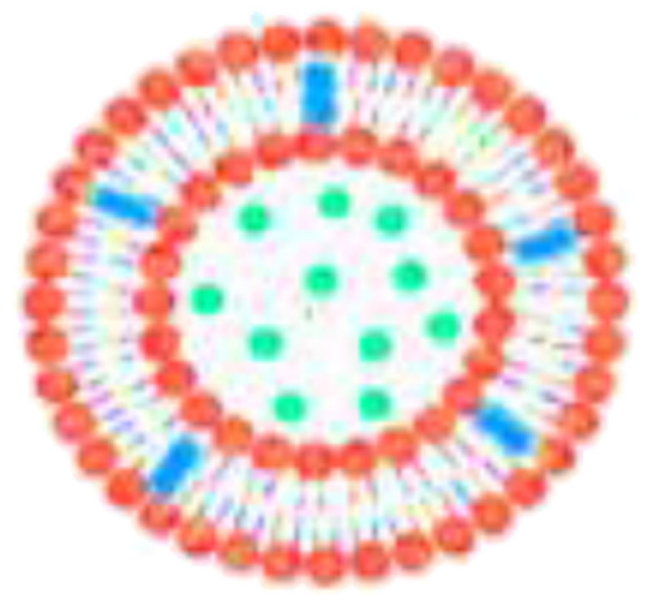

Eg: quercetin-loaded nanostructured lipid carrier (nanostructured lipid carriers are produced from a blend of solid and liquid lipid) [81]

1. Stearylamine and diacetyl phosphate
Application

Liver toxicity and diminished lipid peroxidation Leukemia and bone cancer

HIV-reverse transcriptase and hepatitis C

Fungi and type 1 diabetes

Colorectal cancer

Gram-positive bacteria 
Table 2 Application of different types of nanoparticles (Continued)

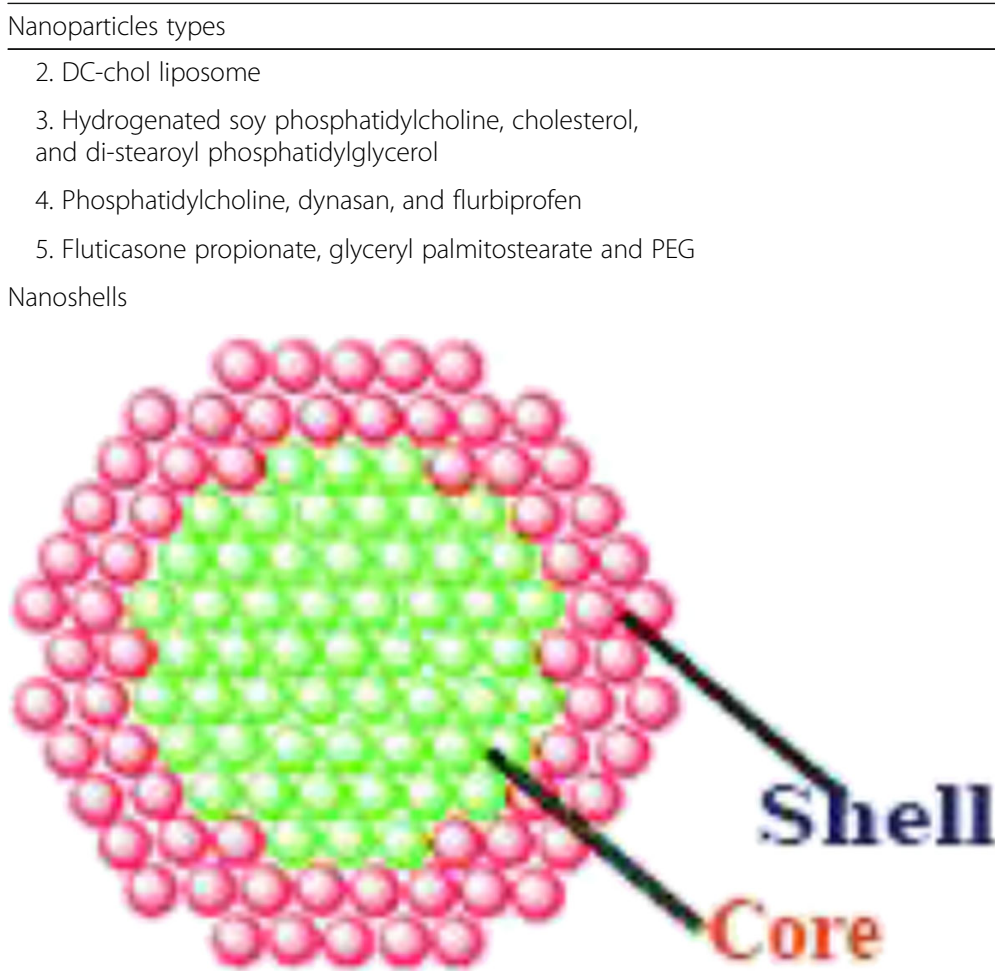

Eg: Artemisinin nanoshells, Radix Salvia miltiorrhiza nanoshell

(Spherical core, surrounded by a shell or outer coating of a thin layer of another materials)

1. Silica coating of silver colloids

2. Gold nanoshell particles

3. Silver nanoshells, silica-silver core-shell particles

4. Nanoshell

Quantum dots

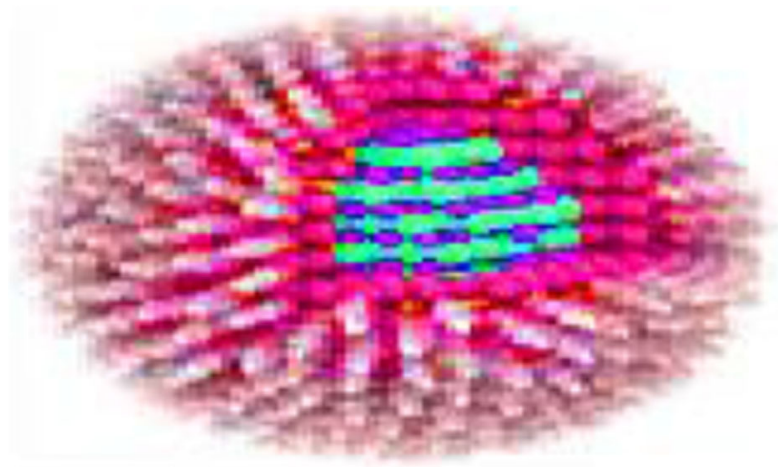

(Semiconductor nanocrystals and core shell nanocrystals containing interface between different semiconductor materials)

1. Quantum dots [83]

2. PEG-encapsulated QDs

3. QDs encapsulated in phospholipid micelles

Superparamagnetic nanoparticles
Application

Gene transfer in subcutaneous tumor

Gram-negative bacteria

Sustained release of anti-inflammatory drug

Topical cortico-therapy

Stability of colloids

Imaging of disease

To detect antibodies and microorganism [82]

To detect cancer cell and tumors
For measuring protein conformational changes, protein interaction, use in immune assay

In vivo animal imaging, lymph node mapping

Cell tracking and color imaging of liver cells 
Table 2 Application of different types of nanoparticles (Continued)

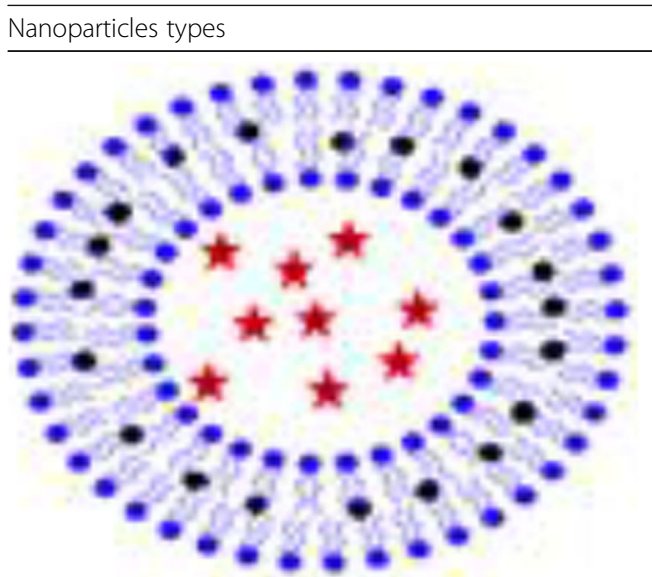

Eg: Hyaluronic acid-loaded superparamagnetic nanoparticles [84] (molecules are those attracted to a magnetic field)

1. Superparamagnetic iron oxide nanoparticles

2. Colloidal dispersion of superparamagnetic iron oxide nanoparticles

3. Superparamagnetic iron oxide nanoparticles coated with polyvinyl benzyl

Dendrimers

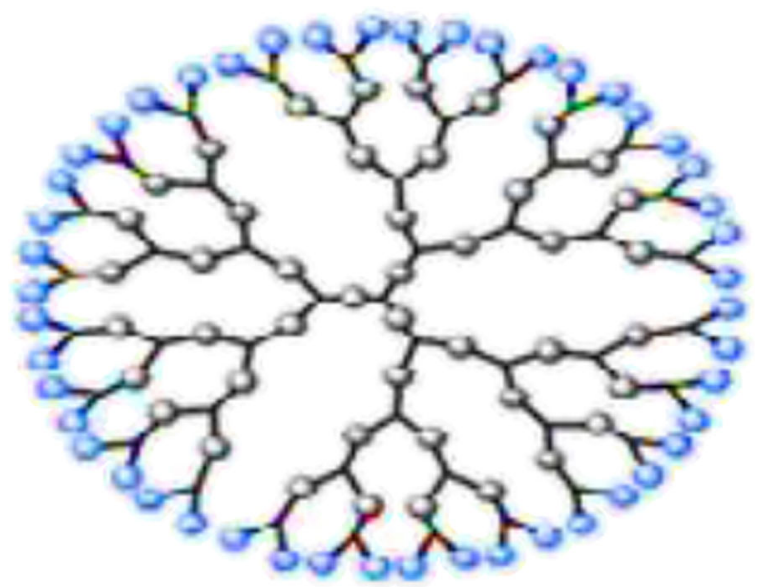

Eg: lactoferrin-tagged quantum dots [85]

(unimolecular, monodisperse, micellar

nanostructures, around $20 \mathrm{~nm}$ in size) [86]

1. Polyamidoamine dendrimers

2. Polylysine dendrimer

3. Pegylated lysine-based copolymeric dendrimer [87]
Magnetic particle imaging

Magnetic fluid hyperthermia

Liver targeting MRI contrast agent
Various bacteria

Glaucoma

Antifungal agent

\section{Conclusion}

Nanoparticles currently have a highly attractive raised area or a diverse range of biological applications. The foregoing shows that nanoparticulate systems have immense potentials, being able to alter poorly soluble, poorly absorbed, and labile biologically active material into capable delivery drugs. The foundation of this system can enfold a variety of active constituent, enzymes, genes and is characterized by an extended circulation time due to the hydrophilic covering which prevents identification by the reticular-endothelial system. To optimize this drug delivery system, a better understanding of the dissimilar mechanisms of biological connections, and particle engineering is still requisite. Additional advances are needed in array to revolve the perception of nanoparticle technology into a reasonable practical relevance as the subsequent generation of the drug delivery system. 
Table 3 Application of nanoparticles in various fields

\begin{tabular}{ll}
\hline Nanoparticles & Application \\
\hline Drug delivery & Nanoparticle enhanced delivery of the drug to uptake by target cells \\
& Reduce the toxicity of free drug to non-target organs [89] \\
Food & Improvement of food safety [90], enhancement of nutrition and flavor, longer shelf lives \\
& Enhancing the bioavailability of nutrients [91] \\
Gene delivery & Efficiently introduce a gene of interest to express its encoded protein in a suitable host or host cell [92] \\
& Mainly employ viral vectors \\
Cancer treatment & Maybe utilize to set in motion photosensitive therapeutic agent for application in cancer treatment [93, 94] \\
Cosmetics & Sunscreen, lotions, etc. \\
Industrial engineering and chemical & Nanoscale materials have been involved in window glass, sunglasses, car bumpers, paints, coatings, sports \\
engineering & gods, explosives, propellants [95], etc. \\
Catalysis & Nanoparticles hold high exterior area that offers elevated catalytic activity [96] \\
Tissue engineering & Repair of damaged tissues \\
Construction & Nanosilica is mixed with the normal concrete to improve the mechanical property and also improve \\
& durability [62] \\
Renewable energy and environmental & Used to treat the surface water by disinfection, purification, and desalination [97-99] \\
remediation &
\end{tabular}

\section{Abbreviations}

GPI: G-protein-coupled receptor; HPLC: High-performance liquid chromatography; MRI: Magnetic resonance imaging; NP: Nanoparticles; NMR: Nuclear magnetic resonance; PEG: Polyethylene glycol; PLGA: Poly lactic glycolic acid; Qd: Quantum dots; SLN: Solid lipid nanoparticles; SEM: Scanning electron microscope; UV: Ultraviolet-visible light; WHO: World Health Organization

\section{Acknowledgements}

I sincerely thank Dr. U. Ubaidulla, Associate professor, Department of Pharmaceutics, who provoked me to write this comprehensive review article.

\section{Authors' contributions}

VS contributed to designing the work in a stepwise manner.

UU gave an eminent idea for the content needed to write this current manuscript.

All authors have read and approved the manuscript.

\section{Funding}

Not applicable

\section{Availability of data and materials}

All data and materials are available upon request.

\section{Ethics approval and consent to participate}

Not applicable

\section{Consent for publication}

Not applicable

\section{Competing interests}

The authors declare that they have no competing interests.

Received: 14 April 2020 Accepted: 30 June 2020

Published online: 12 August 2020

\section{References}

1. Yadav D, Suri S, Choudhary AA, Sikander M, Hemant BNM (2011) Novel approach: herbal remedies and natural products in pharmaceutical science as nano-drug delivery systems. Int J Pharm Tech 3:3092-3116

2. Elzoghby A, Samy W, Elgindy N (2012) Protein-based nanocarriers as promising drug and gene delivery systems. Journal of controlled release 161(1):38-49
3. Singh RP, Singh SG, Naik H, Jain D, Bisla S (2014) Herbal excipients in novel drug delivery system. Int I Comprehensive Pharm 2:1-7

4. Kumar K, Rai AK (2012) Miraculous therapeutic effects of herbal drugs using novel drug delivery systems. Int Res J Pharm 3(2):27-30

5. Kharat A (2014) Novel drug delivery system in herbals. Intl. J. of Pharmaceutical and Biological science 4(4):910-930

6. Swamy MK, Sinniah UR (2016) Patchouli (Pogostemon cablin Benth.): botany, agrotechnology, and biotechnological aspects. Ind Crops Prod 87:161-176

7. Siddiqui AA, Iram F, Siddiqui S, Sahu K (2014) Role of natural products in the drug discovery process. Int J Drug Dev Res 6(2):172-204

8. Nalla A, Chinnala KM (2017) Novel herbal drug delivery system-an overview. WJPPS 6(8):369-395

9. Diana Kozlova (2013) Biological targeting with nanoparticles: state of the art Bio Nano Mat. 14(3-4):161-170. https://doi.org/10.1515/bnm-2013-0020.

10. Bonifacio BV, Silva PB, Dos Santos Ramos MA, Negri KMS, Bauab TM (2014) Nanotechnology-based drug delivery systems and herbal medicines: a review. Int J Nanomed 9:1-15

11. Watkins R, Zhang C, Davis RM, Xu B (2015) Natural product-based nanomedicine: recent advances and issues. Int J Nanomed 10:6055

12. Joseph RR, Venkatraman SS (2017) Drug delivery to the eye: what benefits do nanocarriers offer? Nanomedicine 12:683-702

13. Zhang H, Li Q, Liu R, Zhang X, Li Z, Luan Y (2018) A versatile prodrug strategy to in situ encapsulate drugs in MOF nanocarriers: a case of cytarabine-IR820 prodrug encapsulated ZIF-8 toward chemo-photothermal therapy. Adv Funct Mater 28(35):1802830. https://doi.org/10.1002/adfm.201802830

14. Huiyuan Zhang, Jing Zhang, Qian Li , Aixin Song, Hailong Tian, Jiqian Wang, Zhonghao Li, Yuxia Luan (2020) Site-specific MOF-based immunotherapeutic nanoplatforms via synergistic tumor cells-targeted treatment and dendritic cells-targeted immunomodulation. Biomaterials 245:119983. https://doi.org/10.1016/j.biomaterials.2020.119983

15. Hu X, Tian H, Jiang W, Song A, Li Z, Luan Y (2018) Rational design of IR820and Ce6-based versatile micelle for single NIR laser-induced imaging and dual-modal phototherapy. Small 14(52):1802994. https://doi.org/10.1002/ smll.201802994

16. Salatin S, Yari Khosroushahi A (2017) Overviews on the cellular uptake mechanism of polysaccharide colloidal nanoparticles. J Cell Mol Med 21: 1668-1686

17. Vallianou NG, Evangelopoulos A, Schizas N, Kazazis C (2016) Potential anticancer properties and mechanisms of action of curcumin. Anticancer Res 35:645-651

18. Akhand Pratap Singh (2019) Targeted therapy in chronic diseases using nanomaterial-based drug delivery vehicles. Signal Transduction and Targeted Therapy 4:33. https://doi.org/10.1038/s41392-019-0068-3 
19. Verma $H$, Singh $H$ (2013) Herbal drug delivery system: A modern era prospective. IJCPR 4(3):88-101

20. Aarti P, Nikam Mukesh P, Ratnaparkhiand Shilpa P (2014) Nanoparticles - an overview. Int J Res Dev Pharm Lif Sci 3(5):1121-1127

21. Aggarwal D, Nautiyal U (2016) Ethosomes: A review. Int J pharm med res 4: 354-363

22. Shrivastava AK, Srivastava AK, Prakash D (2014) Herbal immunomodulators: a review. Int J pharm sci res 5:1192-1207

23. Rahman HS, Othman HH (2020) Novel drug delivery systems for loading of natural plant extracts and their biomedical applications. Int J nanomed 15: 2439-2483

24. Goyal A, Kumar S, Nagpal M, Singh I, Arora S (2011) Potential of novel drug delivery systems for herbal drugs. Ind J pharm edu res 45:225-235

25. Campos DA, Madureira AR, Sarmento B, Gomes AM, Pintado MM (2015) Stability of bioactive solid lipid nanoparticles loaded with herbal extracts when exposed to simulated gastrointestinal tract conditions. Food Res Int 78:131-140

26. Belletti D, Riva G, Luppi M, Tosi G, Forni F, VandelliMA RB (2017) Anticancer drug-loaded quantum dots engineered polymeric nanoparticles: diagnosis/ therapy combined approach. Eur J Pharm Sci 107:230-239

27. Ajazuddin SS (2010) Applications of novel drug delivery system for herbal formulations. Fitoterapia 81(7):680-689

28. Calvo P, Remunan Lopez C (1997) Novel hydrophilic chitosanpolyethylene oxide nanoparticles as protein carrier. J Appl Polymer Sci 63:125-132

29. Catarina PR, Ronald JN (2006) Nanoencapsulation: method of preparation of drug-loaded polymeric nanoparticles. Nanotech Bio Med 2:8-21

30. Yoo HS, Park TG (1999) Biodegradable nanoparticles containing PLGA conjugates for sustained release. Pharm Res 16:1114-1118

31. Kumari B (2018) A Review on nanoparticles: Their preparation method and application. Ind Res J Pharm Sci 5(2):1420

32. Shankar S, Rhim JW (2015) Amino acid-mediated synthesis of silver nanoparticles and preparation of antimicrobial agar/silver nanoparticles composite films. Carbohydr Polym 130:353-363

33. Davatgaran-Taghipour Y, Masoomzadeh S, Farzaei MH (2017) Polyphenol nanoformulations for cancer therapy: experimental evidence and clinical perspective. Int J Nanomed 12:2689

34. Taghipour YD, Bahramsoltani R, Marques AM (2018) A systematic review of nanoformulation of natural products for the treatment of inflammatory bowel disease: drug delivery and pharmacological targets. Daru J Pharm Sci 26(2):229-239

35. Hazzah HA, Farid RM, Nasra MMA, HazzahWA E-MMA (2015) Gelucire-based nanoparticles for curcumin targeting to oral mucosa: preparation, characterization, and antimicrobial activity assessment. J Pharm Sci 104: 3913-3924

36. Teskac K (2009) The evidence for solid lipid nanoparticles mediated cell uptake of resveratrol. Int J pharm10:1-9.

37. Zhao J, Martina H (2018) Entry of nanoparticles into cells: the importance of nanoparticles properties. Poly chem. 9:259-272

38. Foroozandeh $P$ (2018) Insight into cellular uptake and intracellular trafficking of nanoparticles. Nanoscale Res Lett 13:339

39. Mukundan D, Mohankumar R, Vasanthakumari R (2015) Green synthesis of silver nanoparticles using leaves extract of Bauhinia tomentosa Linn and its in vitro anticancer potential. Mat Today Proc 2:4309-4316

40. Chaudhary H, Kohli K, Kumar V (2016) Nano-transfersomes as a novel carrier for transdermal delivery. Int J Pharm. 454:367-380

41. Gugulothu D, Kulkarni A, Patravale V, Dandekar P (2013) pH-sensitive nanoparticles of curcumin-celecoxib combination: evaluating drug synergy in an ulcerative colitis model. J Pharm Sci 103:687-696

42. Behzadi S, Serpooshan V (2017) Cellular uptake of nanoparticles: journey inside the cell. Chem Soc Rev 46:4218-4244

43. Domínguez-Villegas V, Clares-Naveros B, García-López ML, Calpena Campmany AC, Bustos-Zagale P (2014) Development and characterization of two nano-structured systems for topical application of flavanones isolated from Eysenhardtiaplatycarpa. Colloid Surface 116: 183-192

44. Mukerjee A, Vishwanatha JK (2009) Formulation, characterization and evaluation of curcumin-loaded PLGA nanospheres for cancer therapy. Anticancer Res 29:3867-3875

45. Youfang C, Xianfu L, Hyunjin P, Richard G (2009) Evaluation of artemisnin nanoparticles. Nanomed Nanotechnol Biol Med 5:316-322
46. Habtemariam S (2020) Recent advances in berberine inspired anticancer approaches: From drug combination to novel formulation technology and derivation. Molecules 25:1426

47. Song YM, Ping QN, Wu ZH (2005) Preparation of silybin nano emulsion and its pharmacokinetics in rabbits. J Chin Pharm Univ 5:427-431

48. Xiao L, Zhang $\mathrm{YH}$, Xu JC, Jin XH (2008) Preparation of floating rutin-alginatechitosan microcapsule. Chin Trad Herb Drugs 2:209-212

49. Min KH, Park K, Kim YS, Bae SM, Lee S (2008) Hydrophobically modified glycol chitosan nanoparticles-encapsulated camptothecin enhance the drug stability and tumor targeting in cancer therapy. J Control Release 127:208218

50. Chao P, Deshmukh M, Kutscher HL, Gao D, Rajan SS (2010) Pulmonary targeting microparticulate camptothecin delivery system: anticancer evaluation in a rat orthotopic lung cancer model. Anticancer Drugs 21:6576

51. Sanli O, Karaca I, Isiklan N (2009) Preparation, characterization, and salicylic acid release behavior of chitosan/poly (vinyl alcohol) blend microspheres. J Appl Polym Sci 111:2731-2740

52. Maiti K, Mukherjee K, Gantait A, Saha BP, Mukherjee PK (2007) Curcuminphospholipid complex: preparation, therapeutic evaluation and pharmacokinetic study in rats. Int J Pharm 330:155-163

53. Goyal C, Ahuja M, Sharma SK (2011) Preparation and evaluation of antiinflammatory activity of gugulipid-loaded proniosomal gel. Acta Pol Pharm Drug Res 68:147-150

54. Liu M, Li H, Luo G, Liu Q, Wang Y (2008) Pharmacokinetics and biodistribution of surface modification polymeric nanoparticles. Arch Pharm Res 31:547-554

55. Xiaoyan A, Jun Y, Min W, Haiyue Z, Li C, Kangde Y (2008) Preparation of chitosan-gelatin scaffold containing tetrandrine-loaded nano-aggregates and its controlled release behavior. Int J Pharm 350:257-264

56. Vicentini FT, Simi TR, Del Ciampo JO, Wolga NO, Pitol DL (2008) Quercetin in w/o microemulsion: in vitro and in vivo skin penetration and efficacy against UVB-induced skin damages evaluated in vivo. Eur J Pharm Biopharm 69:948-957

57. Yadav D, Suri S, Choudhary AA, Sikander M, Heman, Beg MN (2011) A novel approach, herbal remedies, and natural products in pharmaceutical science as nano-drug delivery systems. International Journal of Pharm Tech Research. 3(3):1045-1055

58. Beutler JA (2009) Natural products as a foundation for drug discovery. Curr Prot Pharmacol 46(1):9-11

59. Kinghorn AD, Pan L, Fletcher JN, Chai H (2011) The relevance of higher plants in lead compound discovery programs. J Nat Prod 74:1539-1555

60. Israeli-Lev G, Livney YD (2014) Self-assembly of hydrophobin and its coassembly with hydrophobic nutraceuticals in aqueous solutions: towards application as delivery systems. Food Hydrocoll 35:28-35

61. Nagpa M (2011) Potential of novel drug delivery system for herbal drugs. Ind J Pharm Edu Res 45(3):225

62. Smetana AB, Klabunde KJ, Sorensen CM (2015) Synthesis of spherical silver nanoparticles by digestive ripening, stabilization with various agents, and their 3-D and 2-D superlattice formation. J Colloid Interface Sci 284(2):521526

63. Eustis S, MA El-S (2016) Why gold nanoparticles are more precious than pretty old: noble metal surface plasmon resonance and its enhancement of the radiative and nonradiative properties of nanocrystals of different shapes. ChemSoc Rev 35(3):209

64. Kharisov BI, Dias HR, Kharissova OV (2014) Solubilization, dispersion and stabilization of magnetic nanoparticles in water and nonaqueous solvent: recent trends 4:45354-45381.

65. Lal Pal S, Utpal J (2011) Nanoparticle: An overview of preparation and characterization. JAPS 1(6):228-234

66. Khogta S, Patel J (2019) Herbal nanoformulations or topical delivery. Journal of Herbal Medicine 4:309-318

67. Kumar S, Dilbaghi N, Saharan R, Bhanjana G (2015) Nanotechnology as an emerging tool for enhancing the solubility of poorly water-soluble drugs. J Bionanosci 2:227-250

68. Khatak S, Dureja H (2015) Recent techniques and patents on solid lipid nanoparticles as a novel carrier for drug delivery. Recent Pat Nanotechnol 9: 150-177

69. Teja VC, Chowdary VH, Raju YP, Surendra N, Vardhan RV, Reddy BK (2014) A glimpse of solid lipid nanoparticles as drug delivery systems. J Global Trends Pharm Sci 5:1649-1657 
70. Yadav M, Bhatia VJ, Doshi G, Shastri K (2014) Novel techniques in herbal drug delivery systems. Int J Pharm Sci Rev Res 28(2):83-89

71. Bonifacio BV, Bento PS, Dos MA, Ramos S, Bauab TM, Chili M, Negri S (2014) Nanotechnology-based drug delivery systems and herbal medicines: a review. Int J Nanomedicine 9(1):1-15

72. Mukherjee PK, Harwansh RK, Bhattacharyya S (2015) Bioavailability of herbal products: approach toward improved pharmacokinetics. Evidence-Based Validation of Herbal Medicine. Asian j pharm sci 3:217-226

73. Devi VK, Jain N, Valli KS (2014) Importance of novel drug delivery systems in herbal medicines. Pharmacogn Rev 4(7):27-31

74. Schwarz Luo Y, Chen D, Ren L, Zhao X, Qin J (2016) Solid lipid nanoparticles for enhancing vinpocetine's oral bioavailability. J Controlled Release 114:5359

75. Butani D, Yewale C, Misra A (2016) Topical Amphotericin B solid lipid nanoparticles: design and development. Colloids Surf B 139:17-24

76. De Assis N, Mosqueira F, Vilela C, Andrade S, Cardoso N (2018) Release profiles and morphological characterization by atomic force microscopy and photon correlation spectroscopy of 99mTechnetium-fluconazole nanocapsules. Int J Pharm 349:152-160

77. Mehnert W, Mader K (2012) Solid lipid nanoparticles: production, characterization, and applications. Adv Drug Delivery Rev 64:83-101

78. Patravale VB, Mirani AG (2019) Preparation and characterization of solid lipid nanoparticles-based gel for topical delivery. Pharm Nanotec 3(6):293-302

79. Gokhale MM (2012) Fullerenes:chemistry and its application. Mini rev org chem. 12:42-50

80. Yadav N, Khatak S (2013) Solid lipid nanoparticles - a review. Int J app pharm 5(2):8-18

81. Genicom S, Prchoux A, Correc G, Kervarec N, Simon G, Craigie JS (2018) Carrageenans: new tools for new applications. Blue Biotechnology: Production and Use of Marine Molecules 1:371-416

82. Torchilin VP (2005) Recent advances with liposomes as pharmaceutica carriers. Nat Rev Drug Discov 4:145-160

83. Igor L, Medintz, Clapp A (2008) Potential clinical application s of quantum dots. Int J Nano Med 3(2):151-167

84. Mahmoudi M, Sant S, Wang B, Laurent S, Sen T (2011) Superparamagnetic iron oxide nanoparticles (SPIONs): development, surface modification and applications in chemotherapy. Adv Drug Deliv Rev 63:24-46. https://doi.org/ 10.1016/j.addr.2010.05.006

85. Tomalia DA, Reyna LA, Svenson S (2017) Dendrimers as multipurpose nanodevices for oncology drug delivery and diagnostic imaging. Biochem. Soc. Trans 35(1):61-67

86. Lee CC, MacKay JA, Frechet JMJ, Szoka FC (2005) Designing dendrimers for biological applications. Nat Biotech 23:1517-1526

87. Mintzer MA, Grinstaff MW (2011) Biomedical applications of dendrimers: a tutorial. Chem Soc Rev 40:173-190

88. Zaman M, Ahmad E, Qadeer A (2014) Nanoparticles in relation to peptide and protein aggregation. Int J nanomed 9:899-912

89. Mignani S, El Kazzouli S, Bousmina M, Majoral JP (2013) Expand classical drug administration ways by emerging routes using dendrimer drug delivery systems: a concise overview. Adv Drug Deliv Rev 65:1316-1330

90. He X, Deng H (2019) The current application of nanotechnology in food and agriculture. Journal of food and drug analysis 27(1):1-21

91. Singh T, Shukla S, Kumar P (2017) Application of nanotechnology in food science: perception and overview. Front Microbiol. 8:1501. https://doi.org/ 10.3389/fmicb.2017.01501

92. Ankur Gupta H, Burak Eral T (2016) Nanoemulsions: formation, properties and applications 12: 2826-2841

93. Haque N, Parvez N (2010) Nanotechnology in cancer therapy: a review. J Drug Targ 2:161-168

94. Dimendra J, Pratik A (2012) Treatment of cancer by using nanoparticles as a drug delivery. IJDDR 4(1):14-27

95. Parashar T, Soniya RS (2013) Ethosomes: a recent vesicle of transdermal drug delivery system. Int. J. Res. Dev. Pharm. L. Sci 2(2):285-229

96. Gao L, Jin R (2013) Catalysis by gold nanoparticles: carbon-carbon coupling reactions. Nanotechnol Rev 2(5):529-545

97. Fernanda D, Mohamed F (2018) Nanotechnology for environmental remediation: materials and applications. Molecules 23:1760-1783

98. Khan I (2014) Nanotechnology for environmental remediation. Res J Pharm Bio Chem Sci 5(2):1916
99. Emmanuel A (2016) Nanotechnology as a tool or enhanced renewable energy application in developing countries. J Fundam Renewable Energy Appl 6(6):1-8

\section{Publisher's Note}

Springer Nature remains neutral with regard to jurisdictional claims in published maps and institutional affiliations.

\section{Submit your manuscript to a SpringerOpen ${ }^{\circ}$ journal and benefit from:}

- Convenient online submission

- Rigorous peer review

- Open access: articles freely available online

High visibility within the field

- Retaining the copyright to your article

Submit your next manuscript at $\boldsymbol{\nabla}$ springeropen.com 